\title{
Toward a Generalized Correlation for Liquid-Vapor Two-Phase Frictional Pressure Drop Across Staggered Micro-Pin-Fin Arrays
}

\author{
Christopher A. Konishi, Weilin Qu* \\ Department of Mechanical Engineering \\ University of Hawaii at Manoa \\ Honolulu, Hawaii 96822
}

\begin{abstract}
In a previous study by the corresponding author and co-worker [1] (J. Mita, W. Qu, Pressure drop of water flow across a micro-pin-fin array part 2: adiabatic liquid-vapor two-phase flow, International Journal of Heat and Mass Transfer 89 (2015) 1007-1015), a modified Martinelli-Chisholm type correlation was developed to predict adiabatic water liquid-vapor twophase frictional pressure drop across an array of staggered circular micro-pin-fins. This work expands on the study in ref. [1] and examines whether the correlation is geometry specific or it can be extended to describe a different array configuration. A square micro-pin-fin array were prepared, and adiabatic water liquid-vapor two-phase frictional pressure drop across the array was experimentally investigated. The square pin-fins were 200 microns in side length, 670 microns in height, and 400 microns in both longitudinal and transverse pitches. Two-phase friction multiplier and Martinelli parameter were calculated based on the measured pressure drop as well as a single-phase friction factor correlation developed for the same square array. An excellent agreement was found between the experimental data and correlation predictions despite the distinctive geometrical features possessed by the two sets of micro-pin-fin arrays. The result points to the possibility of establishing the correlation as a generalized one applicable to a broad range of staggered micro-pin-fin array configurations.
\end{abstract}

Keywords: micro-pin-fins, heat sink, two-phase frictional pressure drop, two-phase friction multiplier, Martinelli parameter

* Author to whom correspondence should be addressed, Tel: (808) 956-6332, Fax (808) 9562373, E-mail: qu@hawaii.edu 


\section{Nomenclature:}

$A_{\min } \quad$ Minimum transverse flow area

$A_{p 1}, A_{p 2} \quad$ Flow area of plenums

C C factor in Martinelli-Chisholm type correlations

$D \quad$ Diameter of a circular micro-pin-fin

$f_{s p, f i n} \quad$ Single-phase friction factor

$f_{s p, f, f i n} \quad$ Liquid single-phase friction factor based on actual liquid flow rate

$f_{s p, g, f i n} \quad$ Vapor single-phase friction factor based on actual vapor flow rate

$G_{\max } \quad$ Maximum mass velocity

$G_{p 1}, G_{p 2} \quad$ Mass velocity in plenums

h Enthalpy

$h_{f g} \quad$ Latent heat of vaporization

$h_{v g, \text { in }} \quad$ Enthalpy of the liquid water upstream of the vapor generator

$H \quad$ Height of a micro-pin-fin

$H_{p 1}, H_{p 2} \quad$ Height of plenums

$K_{c 1}, K_{c 2} \quad$ Contraction loss coefficient

$K_{e 1}, K_{e 2} \quad$ Expansion recovery coefficient

$\dot{m} \quad$ Mass flow rate

$M \quad$ Total number of data points

MAE Mean absolute error

$N_{L} \quad$ Total number of micro-pin-fin rows in stream-wise direction

$N_{T, O} \quad$ Number of micro-pin-fins in an odd row

$P \quad$ Pressure

$P_{W, v g} \quad$ Heating power input to vapor generator

$\Delta P \quad$ Pressure drop across test section

$\Delta P_{c 1}, \Delta P_{c 2} \quad$ Contraction pressure loss

$\Delta P_{e 1}, \Delta P_{e 2} \quad$ Expansion pressure recovery

$\Delta P_{\text {fin }} \quad$ Pressure drop across micro-pin-fin array

$\Delta P_{s p, f, f i n} \quad$ Liquid single-phase frictional pressure drop across micro-pin-fin array based on actual liquid flow rate 


$\begin{array}{ll}\Delta P_{s p, g, f i n} & \text { Vapor single-phase frictional pressure drop across micro-pin-fin array based on } \\ & \text { actual vapor flow rate } \\ Q_{l o s s} & \text { Heat loss } \\ R e_{s p} & \text { Single-phase Reynolds number } \\ R e_{s p, f} & \text { Liquid single-phase Reynolds number based on actual liquid flow rate } \\ R e_{s p, g} & \text { Vapor single-phase Reynolds number based on actual vapor flow rate } \\ S & \text { Side length of a square micro-pin-fin } \\ S_{L} & \text { Longitudinal pitch } \\ S_{T} & \text { Transverse pitch } \\ S_{w} & \text { Minimum wall edge to pin center spacing } \\ T & \text { Temperature } \\ V & \text { Specific volume } \\ W_{p 1}, W_{p 2} & \text { Width of plenums } \\ W_{w a l l} & \text { Thickness of thin side walls along test section edges } \\ X_{e} & \text { Thermodynamic equilibrium quality } \\ X & \text { Martinelli parameter } \\ Z & \text { Stream-wise distance }\end{array}$

\section{Greek}

$\phi_{f} \quad$ Two-phase friction multiplier

$\mu \quad$ Dynamic viscosity

\section{Subscripts}

$\begin{array}{ll}\text { avg } & \text { Average } \\ \text { exp } & \text { Experimental } \\ f & \text { Liquid } \\ f g & \text { Difference between liquid and vapor } \\ f i n & \text { Micro-pin-fin array } \\ g & \text { Vapor } \\ i & \text { Stream-wise segment } \\ i b d 0 & \text { Upstream boundary of segment } \mathrm{i}\end{array}$




$\begin{array}{ll}\text { idb1 } & \text { Downstream boundary of segment i } \\ \text { in } & \text { Inlet } \\ \text { out } & \text { Outlet } \\ p_{1} & \text { Deep plenum } \\ p_{2} & \text { Shallow plenum } \\ \text { pred } & \text { Predicted } \\ s p & \text { Single-phase } \\ t p & \text { Two-phase } \\ t s & \text { Test section } \\ v g & \text { Vapor generator } \\ \text { wall } & \text { Side wall }\end{array}$




\section{Introduction}

Transport phenomena associated with flow boiling in micro-pin-fin structures have received considerable research attention in the past decade [2-7]. The underlying objective of these research activities was to develop a fundamental understanding of the transport process that is vital to the design and implementation of two-phase (boiling) micro-pin-fin heat sinks. The novel type of heat sink utilizes micro-pin-fins as its internal heat transfer enhancement structure, and is considered a promising alternative to micro-channel heat sink for high-heat-flux cooling applications.

A number of these previous studies were dedicated to pressure drop characteristics [5-7]. Koşar [5] experimentally investigated refrigerant R-123 flow boiling pressure drop across a staggered hydrofoil micro-pin-fin array. Existing two-phase pressure drop models and correlations were assessed and deemed unable to predict the data. New Martinelli-Chisholm type correlations were proposed for different flow patterns. Qu and Siu-Ho [6] studied water flow boiling pressure drop across a staggered square micro-pin-fin array. Among existing models and correlations, the Martinelli-Chisholm type correlation with a $C$ factor of 5 yielded the best agreement with the data. Reeser et al. [7] studied water and HFE-7200 flow boiling pressure drop across an aligned square and a staggered diamond micro-pin-fin array. Existing correlations were found unable to predict the data. New Martinelli-Chisholm type correlations were proposed for different combinations of working fluid and pin-fin geometry.

With heat induced flow boiling occurring in a micro-pin-fin array, vapor quality would increase appreciably in the stream-wise direction. Reduction in the density of the two-phase mixture leads to an increasing velocity along the flow path. Overall pressure drop across the micro-pin-fin array is thus composed of two components: frictional and accelerational. Accurate determination of the individual components is often a challenge with a variable vapor quality in the stream-wise direction.

To circumvent the difficulty, research efforts have been made to study only the frictional pressure drop by testing adiabatic two-phase flow across micro-pin-fin arrays $[1,8,9]$. In those studies, liquid-vapor (gas) two-phase mixtures with prescribed vapor quality were produced upstream of the micro-pin-fin arrays, and then forced to flow through the structures under adiabatic condition. With negligible stream-wise variation in vapor quality, the accelerational effect was absent, and the overall pressure drop was caused solely by the frictional effect. 
Krishnamurthy and Peles [8] studied frictional pressure drop of adiabatic nitrogen-water two-phase flow across a staggered circular micro-pin-fin array. Existing models and correlations were found unable to predict the data, and a new Martinelli-Chisholm type correlation was proposed. The $C$ factor in the correlation was linearly proportional to liquid Reynolds number. Konishi et al. [9] investigated frictional pressure drop of adiabatic water liquid-vapor two-phase flow across a staggered square micro-pin-fin array. The Martinelli-Chisholm type correlation with a $C$ factor of 5 produced the best agreement among the existing models and correlations.

Mita and $\mathrm{Qu}[1]$ recently studied frictional pressure drop of adiabatic water liquid-vapor two-phase flow across a staggered circular micro-pin-fin array with $D$ of $180 \mu \mathrm{m}, H / D$ of 3.8 , and $S_{L} / D$ and $S_{T} / D$ of 2.2. Experimental results revealed that a unique functional relationship existed between the two-phase friction multiplier $\phi_{f}$ and Martinelli parameter $X$, indicating that the classic Lockhart-Martinelli generalized procedure, originally developed for calculating twophase frictional pressure gradient along pipes [10], could be applied to the circular micro-pin-fin array. The following modified Martinelli-Chisholm type correlation was developed to depict the $\phi_{f}-X$ relationship:

$$
\phi_{7}^{2}=1+\frac{216 \% 3}{x^{2}}+\frac{1}{x^{2}}
$$

The present study expends on the work in ref. [1] by experimentally investigating twophase frictional pressure drop across a staggered array of micro-pin-fins having a square crosssectional shape. The goal is to assess whether the correlation, Eq. (1), is only accurate to the circular array for which it was originally developed, thus geometry specific, or whether the correlation can be extended to describe the present square array. Should latter be the case, Eq. (1) may have the potential to become a generalized correlation applicable to a broad range of staggered micro-pin-fin array configurations.

\section{Experimental Apparatus and Procedure}

\subsection{Test module}

Figure 1(a) shows a schematic of the test module composed of a copper micro-pin-fin test section, a G-7 fiberglass plastic housing, and a polycarbonate plastic (Lexan) cover plate. The test section had a projected top platform area of $3.38 \mathrm{~cm}$ (longitudinal) by $1 \mathrm{~cm}$ (transverse). An array of staggered square micro-pin-fins were micro-end milled out of the top surface. The array contained 85 pin-fin rows in the longitudinal (stream-wise) direction. There were 24 pin-fins in 
every odd transverse row, and 23 pin-fins in every even transverse row. The square pin-fins were $200 \mu \mathrm{m}$ in side length $S, 670 \mu \mathrm{m}$ in height $H$, and $400 \mu \mathrm{m}$ in both longitudinal pitch $S_{L}$ and transverse pitch $S_{T}$. The resulting $H / S$ was 3.35, and $S_{L} / S$ and $S_{T} / S 2$. Figure 1(b) shows a top view and key dimensions of the array.

The test section was inserted into the central portion of the housing. The cover plate was then bolted atop the housing to form a closed flow passage. Leak-proof seal was created by applying a thin layer of room temperature vulcanizing (RTV) silicone rubber along the interfaces between the test section and the housing as well as between the housing and the cover plate. The cover plate was transparent, thus permitting direct visual access to the flow. Once assembled, the test module was wrapped with multiple layers of fiberglass insulation material in an effort to minimize heat loss to the surrounding, thus creating adiabatic testing condition.

The housing contained inlet and outlet plenums, consisting of a shallow and deep section to promote even flow distribution across the micro-pin-fin array. The inlet and outlet deep plenums had a width $W_{p 1}$ of $19 \mathrm{~mm}$ and a height $H_{p 1}$ of $15.9 \mathrm{~mm}$, and the shallow plenums a width $W_{p 2}$ of $19 \mathrm{~mm}$ and a height $H_{p 2}$ of $670 \mu \mathrm{m}$. Within the inlet and outlet deep plenums, two type-K thermocouples were installed to measure the inlet and outlet temperatures $T_{\text {in }}$ and $T_{\text {out }}$, respectively. The $T_{\text {in }}$ and $T_{\text {out }}$ measurements had an estimated uncertainty of $\pm 0.3{ }^{\circ} \mathrm{C}$. An absolute pressure transducer was connected to the inlet deep plenum via a pressure tap to measure the test section inlet pressure $P_{i n}$. A differential pressure transducer was connected to the inlet and outlet deep plenums to measure the pressure drop across the test section $\triangle P$. Uncertainty in both $P_{\text {in }}$ and $\Delta P$ measurements was estimated to be less than $\pm 0.25 \%$ of the readings.

\subsection{Flow loop}

A flow loop as illustrated in Fig. 2(a) was used to supply the working fluid, de-ionized water, to the test module at desired conditions. The water in the reservoir was first deaerated through vigorous boiling for one hour prior to a testing run, and was maintained at the boiling condition throughout the testing run. The water was cooled down to about room temperature using a compact heat exchanger (Heat Exchanger 1) before entering a variable speed gear pump. A 15-micron filter was installed downstream of the pump in an effort to reduce particulate fouling of the micro-pin-fin array. After the filter, the water passed through one of two 
rotameters for flow rate measurements. Additionally, one of two digital flowmeters was used to provide redundant flow rate measurements. A Type-K thermocouple was installed upstream of the digital flowmeters to take water temperature readings for density calculations. The rotameters and digital flowmeters were calibrated using the standard weighting method, and the accuracy of flow rate measurements was better than $\pm 2 \%$ of the readings. Upon leaving the flowmeter, the water flowed through a second compact heat exchanger (Heat Exchanger 2) where its temperature was adjusted to a desired level using a constant temperature bath.

An inline vapor generator was installed between Heat Exchanger 2 and the test module. The temperature of the water entering the vapor generator $T_{v g, \text { in }}$ was measured using a type-K thermocouple. Uncertainty in $T_{v g, \text { in }}$ measurements was estimated to be $\pm 0.3{ }^{\circ} \mathrm{C}$. The vapor generator consisted of a cylindrical immersion heater installed concentrically inside an outer pipe of larger diameter as shown in Fig. 2(b). While flowing through the gap between the immersion heater and outer pipe, the water was vaporized into a saturated liquid-vapor two-phase mixture by the immersion heater that was powered by a 0-110 VAC transformer. The heating power supplied to the heater $P_{W, v g}$ was measured using a precision wattmeter whose accuracy is $\pm 0.5 \%$ of the readings. The vapor generator was well wrapped with fiberglass insulation material to minimize heat loss.

The water liquid-vapor two-phase mixture leaving the vapor generator entered the test module for pressure drop measurements. After the test module, the two-phase mixture flowed through a third heat exchanger (Heat Exchanger 3) to condense any vapor back to liquid before the water returned to the reservoir.

\subsection{Experimental procedure}

\subsubsection{Single-phase tests}

As a single-phase friction factor correlation for the same array is needed in calculating two-phase frictional pressure drop following the Lockhart-Martinelli generalized procedure, a series of testing runs using water liquid single-phase flow were first performed. The vapor generator was not used in the single-phase tests.

Seven water inlet temperatures $T_{i n}$, ranging from $22{ }^{\circ} \mathrm{C}$ to $80{ }^{\circ} \mathrm{C}$, were tested. For each $T_{i n}$, seventeen different maximum mass velocities $G_{\max }$ were tested, ranging from 189 to 1717 
$\mathrm{kg} / \mathrm{m}^{2} \mathrm{~s} . G_{\max }$ was calculated based on the minimum transverse flow area $A_{\min }$ in the micro-pinfin array,

$$
G_{\text {max }}=\frac{\text { mi }}{A_{\text {min }}}
$$

$A_{\min }$ is calculated from

$$
A_{\text {min }}=H\left[\left(N_{\tau Q}-1\right)\left(s_{T}-s^{\prime}\right)+\left(2 s_{W}-s_{)}\right)\right],
$$

where $N_{T, O}$ is the number of pin-fins in an odd transverse row $\left(N_{T, O}=24\right)$, and $S_{W}$ the wall to pin distance for the odd row $\left(S_{W}=200 \mu \mathrm{m}\right)$ as shown in Fig. 1(b). The resulting single-phase Reynolds number $R e_{s p}$, defined in Eq. (4), ranged from 40 to 959.

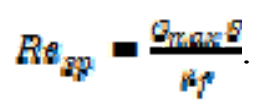

It was observed that the measured $T_{\text {out }}$ was always slightly lower than $T_{\text {in }}$ due to heat loss from the test module. The temperature drops averaged $0.5^{\circ} \mathrm{C}$ with a highest value of $2.9^{\circ} \mathrm{C}$. The water was thus assumed to be isothermal, and the average of $T_{\text {in }}$ and $T_{\text {out }}$ was used to determine water properties.

$$
T_{\text {wQ }}=\frac{T_{i n}+T_{\text {wns }}}{2}
$$

During a testing run, the water liquid flow was first allowed to reach steady state where readings from the digital flowmeters, thermocouples, and pressure transducers became constant. Once at steady state, the readings were taken using an Agilent data acquisition and control unit interfaced to a PC at 0.5-second intervals for a total of 3 minutes, and outputted to an Excel spreadsheet. Readings from the rotameters were recorded manually. The data reported in the paper were the averages of the readings.

\subsubsection{Two-phase tests}

The vapor generator was engaged in the two-phase tests to produce water saturated liquid-vapor two-phase mixtures. The water was in liquid phase at the inlet of the vapor generator, and its temperature $T_{v g, \text { in }}$ was set to be about $90{ }^{\circ} \mathrm{C}$. Eight maximum mass velocities $G_{\max }$, ranging from 189 to $591 \mathrm{~kg} / \mathrm{m}^{2} \mathrm{~s}$, were tested. At each $G_{\max }, P_{W, v g}$ was progressively increased from low to high levels by adjusting the transformer to yield a range of vapor qualities. The following equation is used to determine thermodynamic equilibrium quality of the twophase mixture at the test section inlet $x_{e, i n}$, 


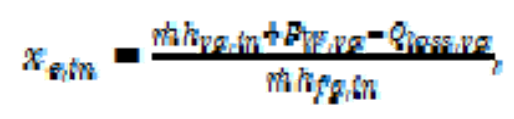

where $h_{v g \text {,in }}$ is the enthalpy of the liquid water entering the vapor generator based on the measured $T_{v g, i n}, Q_{l o s s, v g}$ the heat loss from the vapor generator, and $h_{f g, i n}$ the latent heat of vaporization based on the measured $P_{i n}$. Heat losses from the vapor generator and test module at each $G_{\max }, Q_{\text {loss,vg }}$ and $Q_{\text {loss,ts, }}$, respectively, were characterized through running $90{ }^{\circ} \mathrm{C}$ liquid water through the corresponding two loop components. Qloss,vg ranged from 5.0 to $6.1 \mathrm{~W}$, and was $0.8 \%-5.1 \%$ of $P_{W, v g}$ with an average of $1.5 \%$. Q Q ${ }_{\text {loss,ts }}$ ranged from 5.8 to $6.9 \mathrm{~W}$, and was $0.8 \%$ $6.3 \%$ of $P_{W, v g}$ with an average of $1.8 \%$.

Flow rate, temperature, inlet pressure, and pressure drop readings were recorded at steady state using the Agilent data acquisition unit. Readings from the wattmeter and rotameters were recorded manually.

\section{Results and Discussion}

\subsection{Single-phase frictional pressure drop and friction factor}

Figure 3 presents the measured single-phase pressure drop $\Delta P_{s p}$ versus $G_{\text {max }}$. For a given $T_{i n}, \Delta P_{s p}$ increases with increasing $G_{\max }$ as is to be expected. For a prescribed $G_{\max }, \Delta P_{s p}$ decreases with increasing $T_{i n}$ as a result of decreasing water viscosity $\mu_{f}$.

As the pressure ports were located in the deep inlet and outlet plenums, $\Delta P_{s p}$ was composed of pressure drops across the inlet deep and shallow plenums, micro-pin-fin array, outlet shallow and deep plenums, as well as pressure losses and recoveries associated with the consecutive sections. Neglecting the pressure drops along the plenums, single-phase frictional pressure drop across the micro-pin-fin array $\Delta P_{s p, f i n}$ can be calculated from

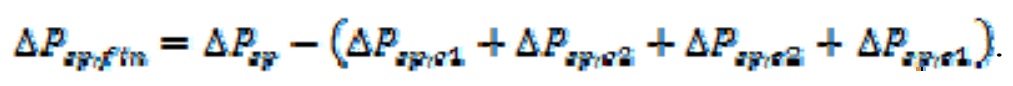

$\Delta P_{s p, c 1}$ and $\Delta P_{s p, c 2}$ in Eq. (7) represent the single-phase inlet contraction losses from the deep to shallow plenum and from the shallow plenum to the micro-pin-fin array inlet, respectively, and are calculated from $[11,12]$,

$$
\Delta P_{p p, 01}=\frac{v_{z}}{2}\left(G_{p 2}^{2}-G_{p 1}^{2}\right)+\frac{\Delta_{\pi q v F}}{2} G_{p 2}^{2},
$$

and

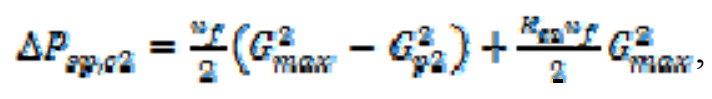


where the subscript $p 1$ and $p 2$ refer to the deep plenum and shallow plenum, respectively. $G_{p 1}$ and $G_{p 2}$ are the mass velocities in the deep plenum and shallow plenum, respectively.

$$
G_{p 1}=\frac{m}{A_{p 1}}=\frac{m}{E_{p 2} W_{p 2}}
$$

and

$$
G_{p 2}=\frac{p h}{A_{p s}}=\frac{p h}{H_{p n} W_{p s}} .
$$

$K_{c 1}$ and $K_{c 2}$ represent the loss coefficients for the corresponding abrupt contractions and are evaluated from $[11,12]$

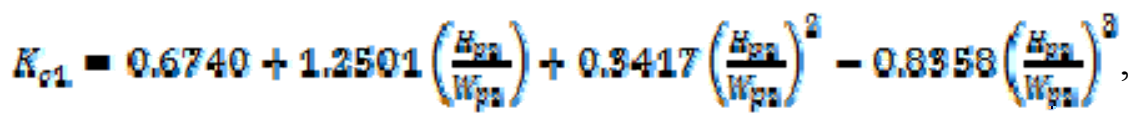

and

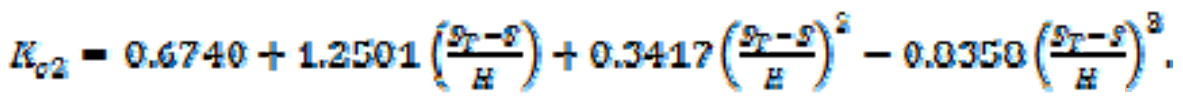

$\Delta P_{s p, e 2}$ and $\Delta P_{s p, e 1}$ are the single-phase outlet expansion recoveries from the micro-pin-fin array outlet to the shallow plenum and from the shallow plenum to the deep plenum, respectively, and are calculated from $[11,12]$

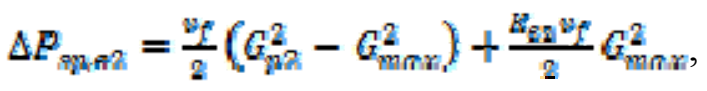

and

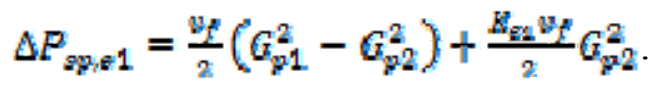

$K_{e 2}$ and $K_{e 1}$ denote the recovery coefficients for the corresponding abrupt expansions, and are evaluated from $[11,12]$

$$
E_{* 2}=\left(1-\frac{A_{\operatorname{man}}}{A_{p a}}\right)^{2}
$$

and

$$
K_{* 1}=\left(1-\frac{A_{\mathrm{rnR}}}{A_{\mathrm{p} 2}}\right)^{2}
$$

The total single-phase contraction loss $\Delta P_{s p, c 1}+\Delta P_{s p, c 2}$ accounts for $0.9 \%-2.3 \%$ of $\Delta P_{s p}$

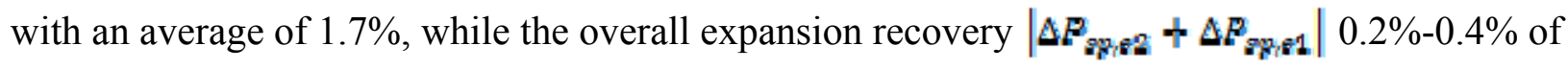
$\Delta P_{s p}$ with an average of $0.3 \%$.

Once $\Delta P_{s p, f i n}$ is obtained from Eq. (7), single-phase friction factor $f_{s p, f i n}$ can be calculated from 


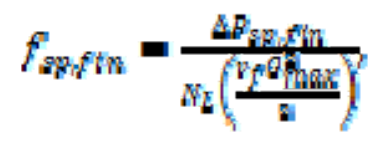

where $N_{L}$ is the total number of pin-fin rows in the stream-wise direction $\left(N_{L}=85\right)$.

Figure 4 plots $f_{s p, f i n}$ versus $R e_{s p}$ data on a log-log scale. $f_{s p, f i n}$ is shown decreasing with increasing $R e_{s p}$ as expected. The data are correlated using the following power series function,

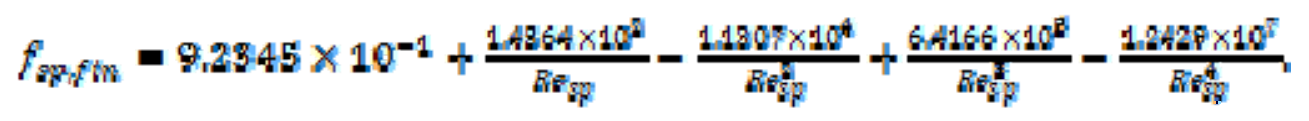

All constants in Eq. (19) were obtained using a non-linear least squares regression. The same power series functional form was originally adopted by Zukauskas and Ulinskas to describe the relationship between friction factor and Reynolds number for single-phase flow across staggered tube banks [13], and later utilized by Mita and Qu to correlate $f_{s p, f i n}$ versus $R e_{s p}$ data for a staggered circular micro-pin-fin array [12]. Equation (19) is presented in Fig. 4 as a solid line.

Figure 5 compares the $f_{s p, f i n}$ versus $R e_{s p}$ data of the present square array with those of the circular array investigated in ref. [12]. The circular array had diameter $D$ of $180 \mu \mathrm{m}, H / D$ of 3.8 , and $S_{L} / D$ and $S_{T} / D$ of 2.2. For a fixed $R e_{s p}, f_{s p, f i n}$ of the present square array is significantly higher than that of the circular array, indicating that the $f_{s p, f i n}-R e_{s p}$ relationship is sensitive to micro-pin-fin configuration. The single-phase friction factor correlation, Eq. (19), is thus geometry specific, and is intended for use in the present study to calculate the two-phase frictional pressure drop.

\subsection{Two-phase frictional pressure drop}

Figure 6 plots the measured two-phase pressure drop $\Delta P_{t p}$ versus inlet vapor quality $x_{e, i n}$ for the eight $G_{\max }$. For a given $G_{\max }, \Delta P_{t p}$ increases substantially with increasing $\chi_{e, i n}$, indicative of a strong impact of the presence of the vapor phase on pressure drop. For a fixed $x_{e, i n}, \Delta P_{t p}$ increases appreciably as $G_{\max }$ increases.

Under the adiabatic condition adopted in the present study, the accelerational pressure drop across the micro-pin-fin array was negligibly small as compared to the frictional pressure drop. It is thus assumed that the two-phase pressure drop across the array was caused solely by the frictional effect. The approximation has been validated in our previous study of the circular array [1]. 
Following Eq. (7), the two-phase frictional pressure drop across the micro-pin-fin array $\Delta P_{t p, f i n}$ can be calculated from

$$
\Delta P_{\text {tp } f \text { in }}=\Delta P_{t p}-\left(\Delta P_{t p, 01}+\Delta P_{t p, e 2}+\Delta P_{t p, e 2}+\Delta P_{t p, e 1}\right)
$$

The losses and recoveries components in Eq. (20) are calculated using the following equations $[1,11]$,

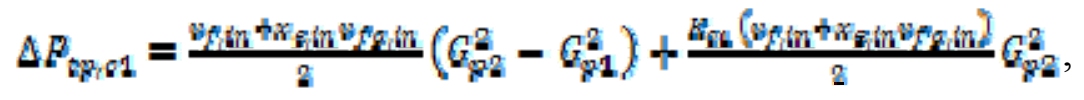

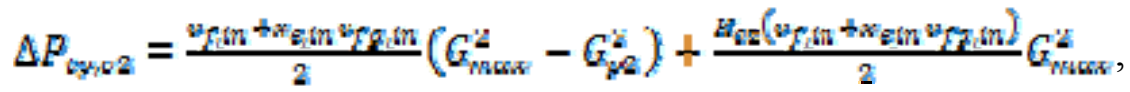

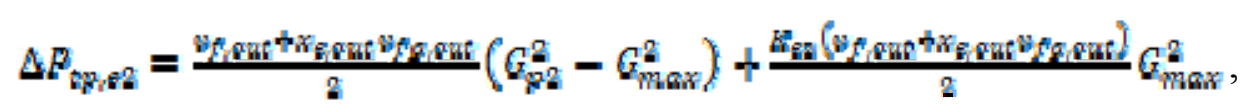

and

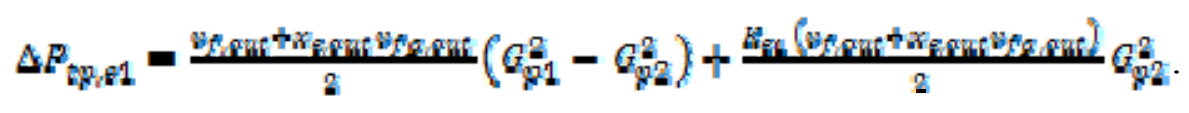

$G_{p 1}, G_{p 2}, K_{c 1}, K_{c 2}, K_{e 2}$, and $K_{e 1}$ are calculated from Eqs. (10)-(13), (16), (17), respectively.

Material properties at the inlet are evaluated based on the measured $P_{i n}$, while properties at the outlet based on $P_{\text {out }}$.

$$
P_{\text {cosc }}=P_{\text {in }}-A P_{b \%} \text {. }
$$

$x_{e, \text { out }}$ in Eqs. (23) and (24) represents the thermodynamic equilibrium quality of the two-phase mixture at the test section outlet:

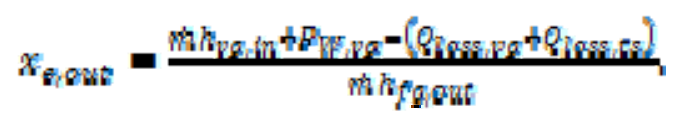

The total two-phase contraction loss $\Delta P_{t p, c 1}+\Delta P_{t p, c 2}$ accounts for $1.9 \%-11.2 \%$ of $\Delta P_{t p}$ with an average of $6.7 \%$, while the overall expansion recovery $\left|\Delta P_{t p, * 2}+\Delta P_{t p, 11}\right| 1.7 \%-6.0 \%$ of $\Delta P_{t p}$ with an average of $3.5 \%$.

\subsection{Two-phase friction multiplier and Martinelli parameter}

Two-phase friction multiplier $\phi_{f}$ and Martinelli parameter $X$ are determined for the present square array using the following equations:

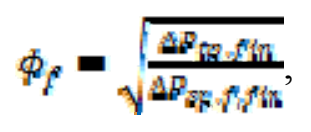

and 


$$
X=\sqrt{\frac{\Delta B_{\text {sustin }}}{\Delta B_{\text {sprofin }}}}
$$

All material properties needed in the calculations are evaluated based on the average of the inlet and outlet pressure,

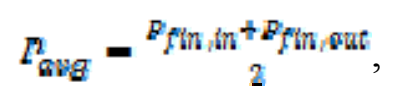

where

$$
E_{f m i n}=P_{t m}-\left(\Delta P_{01}+\Delta P_{o 2}\right)
$$

and

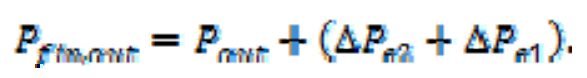

Effect of property variations as a result of decreasing local fluid pressure along the stream-wise direction is accounted for later in the communication.

Two-phase frictional pressure drop across the micro-pin-fin array $\Delta P_{t p, \text { fin }}$ in Eq. (27) is obtained from Eq. (20). $\Delta P_{s p, f, f i n}$ and $\Delta P_{s p, g, f i n}$ in Eqs. (27) and (28) represent liquid and vapor single-phase frictional pressure drop across the micro-pin-fin array, respectively, based on the actual flow rates of the two phases. $\Delta P_{s p, f, f i n}$ and $\Delta P_{s p, g, f i n}$ are evaluated from

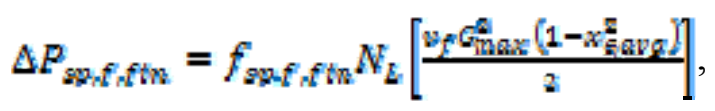

and

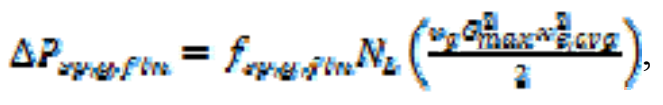

where $f_{s p, f, f i n}$ and $f_{s p, g, f i n}$ denote liquid and vapor single-phase friction factor, respectively, based on the actual flow rates, and are calculated using Eq. (19),

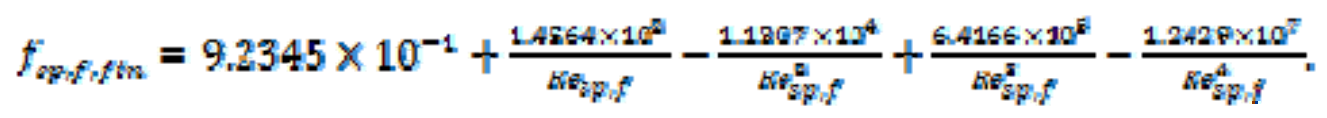

and

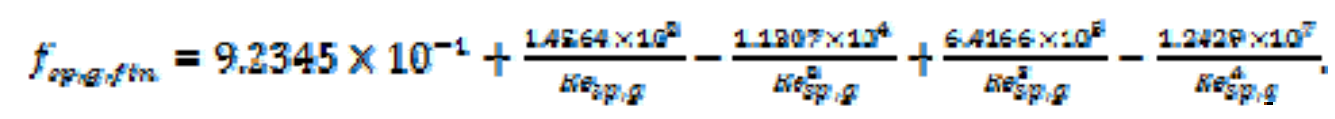

$R e_{s p, f}$ and $R e_{s p, g}$ in Eqs. (34) and (35) denote liquid and vapor Reynolds number, respectively, based on the actual flow rates,

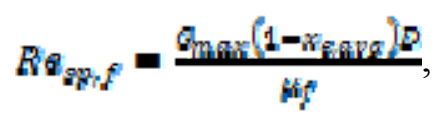

and 


$$
R e_{s p, g}=\frac{Q_{\max \alpha_{G a v g}}}{\mu_{g}} .
$$

$R e_{s p, f}$ ranged from 104 to 477 , and $R e_{s p, g}$ from 41 to 1,071 in the present study. $x_{e, a v g}$ in Eqs. (32),

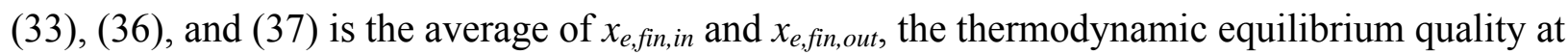
the micro-pin-fin array inlet and outlet, respectively,

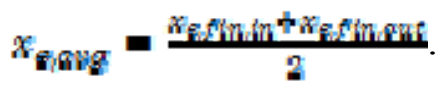

$x_{e, \text { fin,in }}$ and $x_{e, \text { fin,out }}$ are determined from

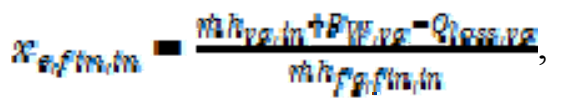

and

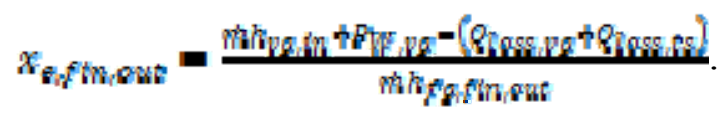

$\phi_{f}$ versus $X$ data are plotted on a log-log scale in Fig. 7. Little scatter is observed in the data, confirming that $\phi_{f}$ can be correlated uniquely as a function of $X$ as observed in ref. [1].

Figure 8 compares the present $\phi_{f}$ versus $X$ data with those of the circular array in ref. [1]. Also presented in Fig. 8 is the modified Martinelli-Chisholm type correlation, Eq. (1), which was developed based on the circular array data [1]. An excellent agreement can be found between the two sets of data, indicating that Eq. (1) is extendable to the present square array. While the observation is based on a rather limited database and it is necessary to perform further experimental validation with a broad selection of micro-pin-fin configurations, fluid types, and flow conditions, the above finding is nevertheless promising in view of the distinctive geometrical features possessed by the two arrays; thus raises the possibility of establishing Eq. (1) as a generalized correlation for two-phase frictional pressure drop across staggered micropin-fin arrays with a broad parametric range.

\subsection{Two-phase pressure drop calculation using the correlation}

The modified Martinelli-Chisholm type correlation, Eq. (1), was applied to calculate twophase frictional pressure drop across the present micro-pin-fin array $\Delta P_{t p, f i n}$. Effect of property variation was accounted for in the calculations using a segment-based technique [1].

$\Delta P_{t p, f i n}$ is calculated from

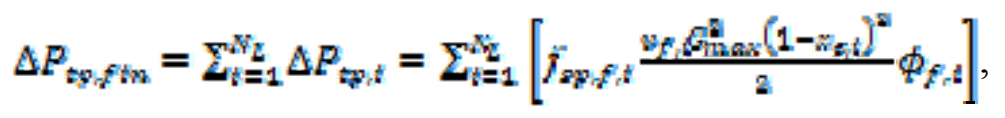


where subscript $i$ denotes a segment in the stream-wise direction that contains a row of micropin-fins together with the surrounding portion of the top and bottom end walls as shown in Fig. 9. Liquid single-phase friction factor based on the actual flow rate $f_{s p, f, i}$, two-phase friction multiplier $\phi_{f, i}$, and thermodynamic equilibrium quality $x_{e, i}$ in the segment $i$ are determined following Eqs. (34), (1), and (38), respectively.

Calculation of $\Delta P_{t p, f i n}$ using Eq. (41) commences at the micro-pin-fin array inlet with local pressure $P_{f i n, i n}$, and proceeds progressively downstream. All material properties in the segment $i$ are determined based on the local pressure $P_{i}$ that is evaluated from

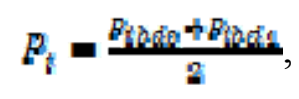

where subscripts $i b d 0$ and $i b d 1$ indicate the upstream and downstream boundary of the segment $i$, respectively, and

$$
P_{t b d 1}=P_{t b d 0}-\Delta P_{t p i t} \text {. }
$$

An iterative technique was applied to determine the local pressure $P_{i}$ and all material properties in each segment $i$.

The overall pressure drop across the test section $\Delta P_{t p}$ is obtained by adding the inlet contraction losses and outlet expansion recoveries to the calculated $\Delta P_{t p, f i n}$. Figure 10 compares the calculated $\Delta P_{t p}$ with the experimental data. A good agreement can be observed with a mean absolute error (MAE) of $15.7 \%$ based on 77 data points. The mean absolute error (MAE) is given by

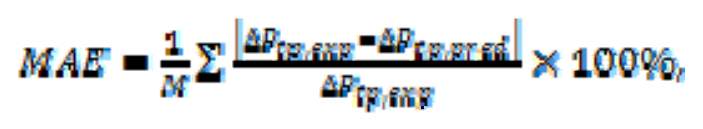

where $M$ is the total number of data points.

It should be noted that applying the Lockhart-Martinelli generalized procedure, i.e., Eq. (41), to calculate two-phase frictional pressure drop across a micro-pin-fin array requires a preexisting single-phase friction factor correlation such as Eq. (19) for the same array. Figure 5 shows that the $f_{s p, f i n}-R e_{s p}$ relationship is sensitive to micro-pin-fin geometry. As a result, a generalized correlation is not available at the present time. A geometry specific correlation could be obtained by using an empirical approach as demonstrated in the present study. Alternative, it has been shown in ref. [12] that a numerical method involving three-dimensional 
simulation could provide an accurate predictive tool; thus can be used to establish such correlations.

\section{Conclusions}

An experimental study was conducted to investigate adiabatic water liquid-vapor twophase frictional pressure drop across a staggered square micro-pin-fin array. The data were used to assess the applicability of a pervious modified Martinelli-Chisholm type correlation developed for a staggered circular micro-pin-fin array. Key findings from the study are as follows:

1. The two-phase friction multiplier was found to be a unique function of Martinelli parameter. The result reinforced the notion that the Lockhart-Martinelli generalized procedure, though originally developed for pipe flow, can be applied to calculate twophase frictional pressure drop across staggered micro-pin-fin arrays.

2. The modified Martinelli-Chisholm type correlation for the circular array could accurately describe the data of the present square array. The result points to the possibility of establishing the correlation as a generalized one that is not tied to a specific micro-pin-fin configuration, thus having a broad application range.

3. Application of the modified Martinelli-Chisholm type correlation to calculate two-phase frictional pressure drop requires a pre-existing single-phase friction factor correlation. Such correlation is geometry specific, and can be established using either an empirical approach or a numerical method.

\section{Acknowledgement}

The authors are grateful for the support of the National Science Foundation (NSF) (Award no. CBET10-34242). The micro-pin-fin test section was fabricated at the Laser-Assisted Multi-Scale Manufacturing Laboratory, University of Wisconsin-Madison. Professor Frank Pfefferkorn's assistance in fabricating the test section was greatly appreciated. 


\section{References}

[1] J. Mita, W. Qu, Pressure drop of water flow across a micro-pin-fin array part 2: adiabatic liquid-vapor two-phase flow, International Journal of Heat and Mass Transfer 89 (2015) 1007-1015.

[2] A. Koşar, Y. Peles, Boiling heat transfer in a hydrofoil-based micro pin fin heat sink, International Journal of Heat and Mass Transfer 50(5-6) (2007) 1018-1034.

[3] S. Krishnamurthy, Y. Peles, Flow boiling of water in a circular staggered micro-pin fin heat sink, International Journal of Heat and Mass Transfer 51 (2008) 1349-1364.

[4] W. Qu, A.M. Siu-Ho, Experimental study of saturated flow boiling heat transfer in an array of staggered micro-pin-fins, International Journal of Heat and Mass Transfer 52 (2009) 1853-1863.

[5] A. Koşar, Two-phase pressure drop across a hydrofoil-based micro pin device using R123, Experimental Thermal and Fluid Science 32 (2008) 1213-1221.

[6] W. Qu, A.M. Siu-Ho, Measurement and prediction of pressure drop in a two-phase micro-pin-fin heat sink, International Journal of Heat and Mass Transfer 52 (2009) 51735184.

[7] A. Reeser, A. Bar-Cohen, G. Hetsroni, High quality flow boiling heat transfer and pressure drop in microgap pin fin arrays, International Journal of Heat and Mass Transfer 78 (2014) 974-985.

[8] S. Krishnamurthy, Y. Peles, Gas-liquid two-phase flow across a bank of micropillars, Physics of Fluids 19(4) (2007) 043302-1-043302-14.

[9] C.A. Konish, W. Qu, F.E. Pfefferkorn, Experimental study of water liquid-vapor twophase pressure drop across an array of staggered micropin-fins, ASME Journal of Electronic Packaging 131 (2009) 021010-1-021010-8.

[10] R.W. Lockhart, R.C. Martinelli, Proposed correlation of data for isothermal two-phase, two-component flow in pipes, Chemical Engineering Progress 45 (1949) 39-48.

[11] R.D. Blevins, Applied Fluid Dynamics Handbook, Van Nostrand Reinhold Company, New York, 1984.

[12] J. Mita, W. Qu, Pressure drop of water flow across a micro-pin-fin array part 1: isothermal liquid single-phase flow, International Journal of Heat and Mass Transfer, 89 (2015) 1073-1082. 
[13] A. Žukauskas, R. Ulinskas, Banks of plain and finned tubes, in: E.U. Schlunder (Eds.), Heat exchanger design handbook, Hemisphere, Washington, 1983, pp. 2.2.4-1-2.2.4-17. 


\section{Figure Captions}

Fig. 1: $\quad$ (a) Test module construction, and (b) top view of micro-pin-fin array.

Fig. 2: $\quad$ Schematics of (a) flow loop and (b) vapor generator.

Fig. 3: Measured single-phase pressure drop versus maximum mass velocity.

Fig. 4: $\quad$ Single-phase friction factor versus Reynolds number.

Fig. 5: Comparison of present single-phase friction factor data with those of a circular array.

Fig. 6: $\quad$ Measured two-phase pressure drop versus inlet vapor quality.

Fig. 7: $\quad$ Two-phase friction multiplier versus Martinelli parameter.

Fig. 8: $\quad$ Comparison of present two-phase friction multiplier data with those of a circular array and correlation predictions.

Fig. 9: $\quad$ Schematic of a segment in micro-pin-fin array.

Fig. 10: $\quad$ Comparison of two-phase pressure drop data with correlation predictions. 


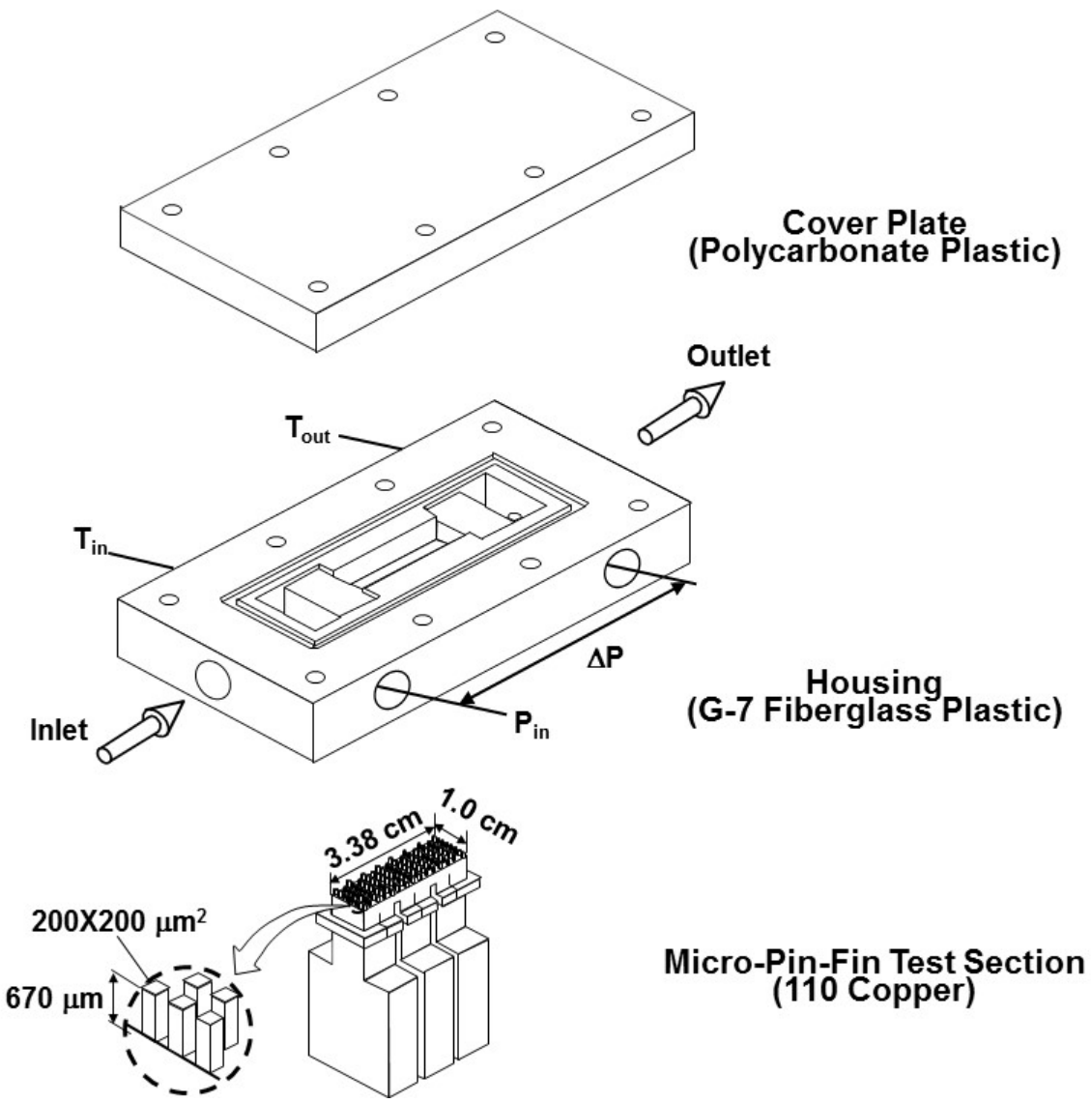

(a)

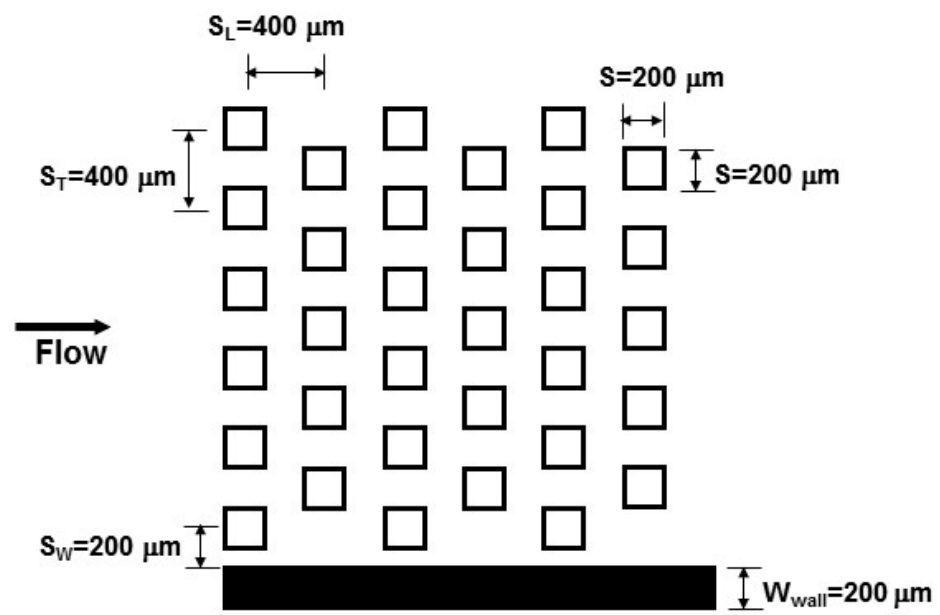

(b)

Fig. 1 


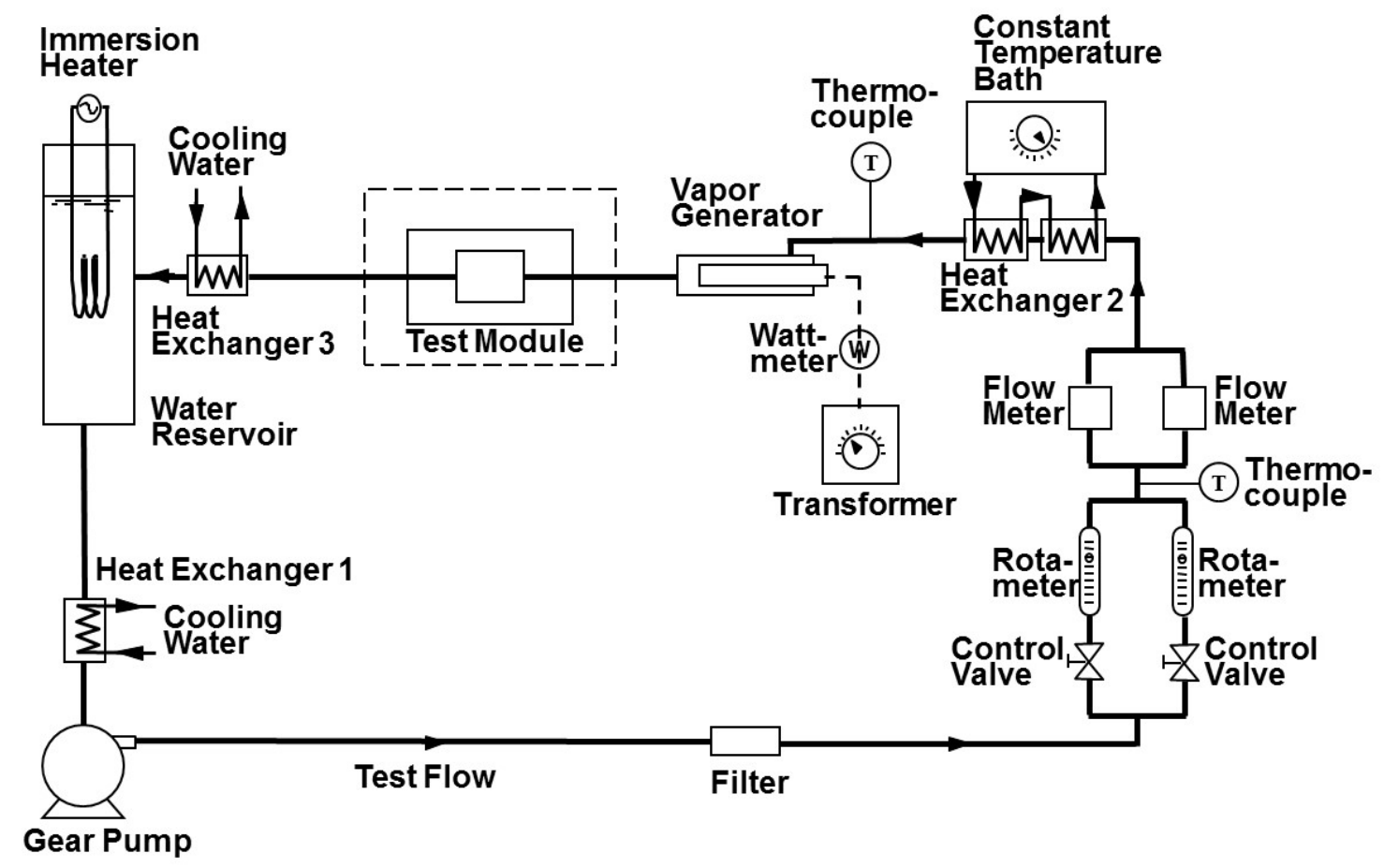

(a)

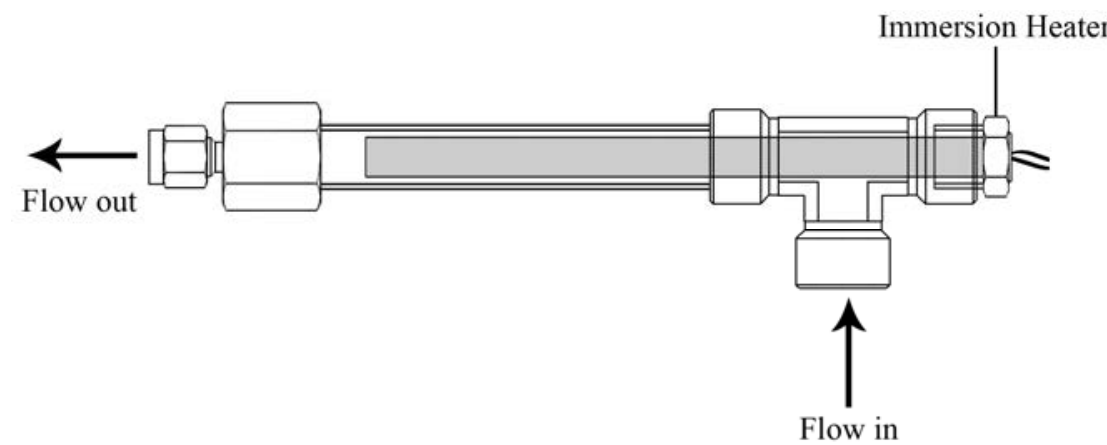

(b)

Fig. 2 


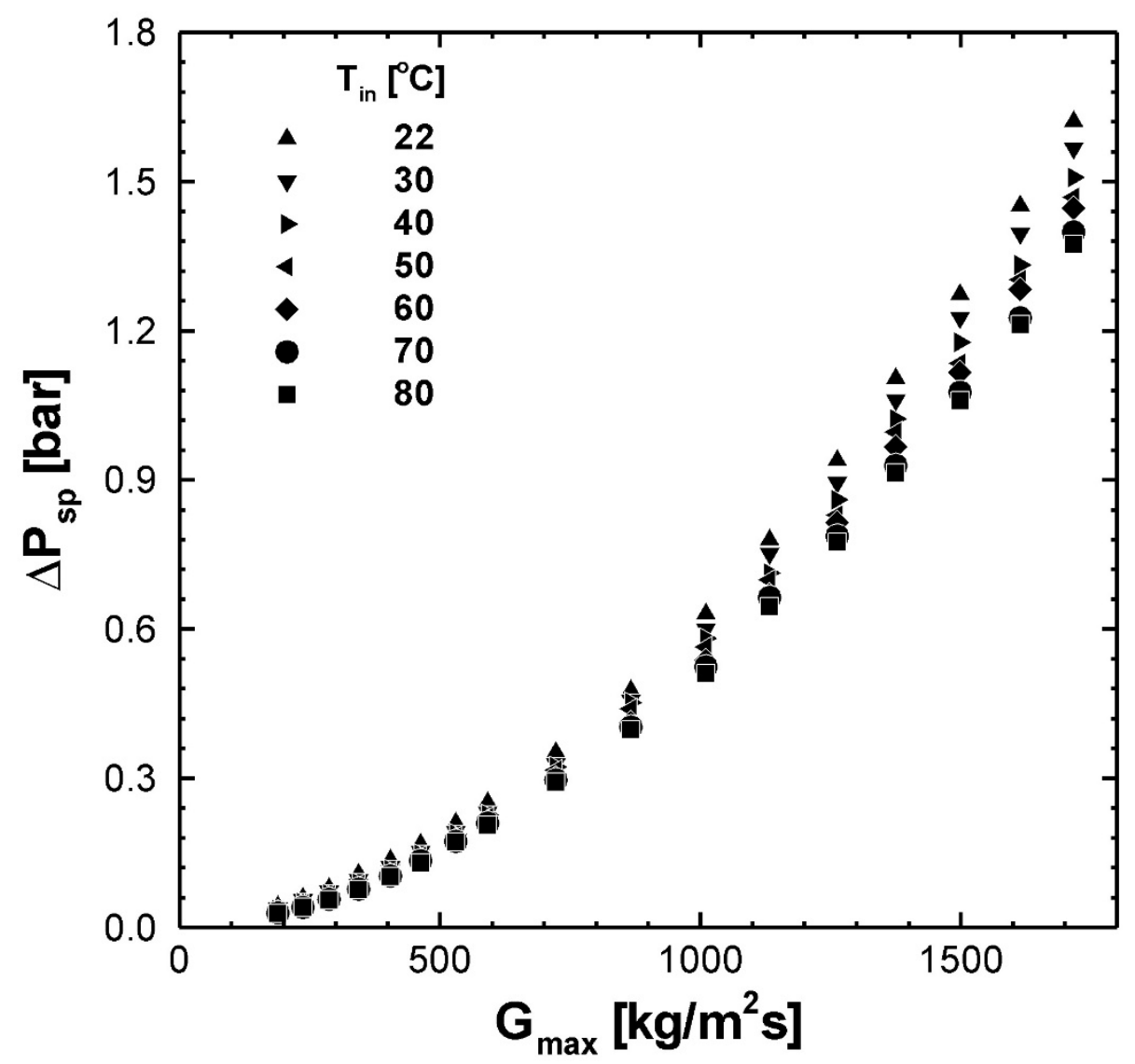

Fig. 3 


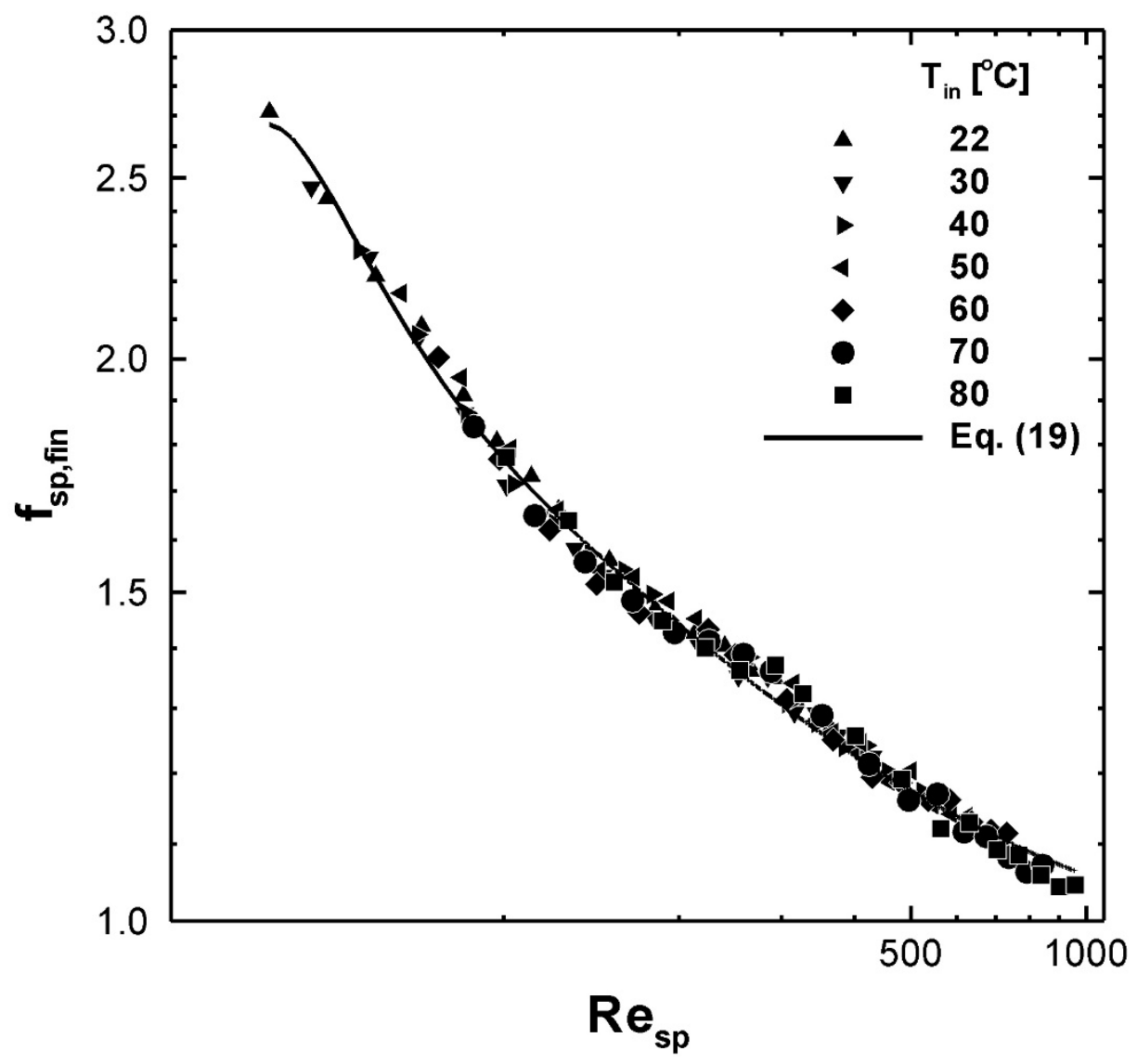

Fig. 4 


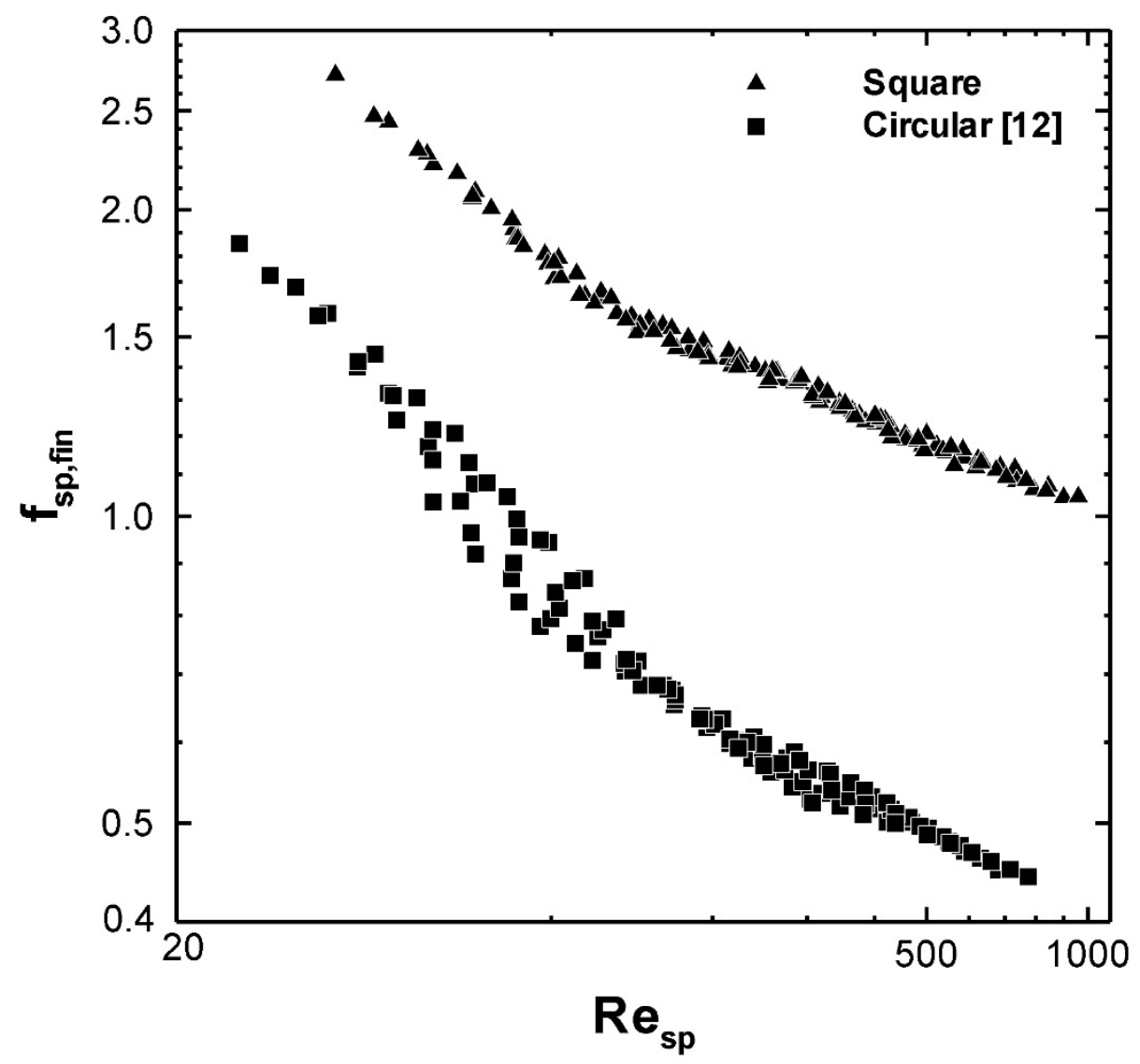

Fig. 5 


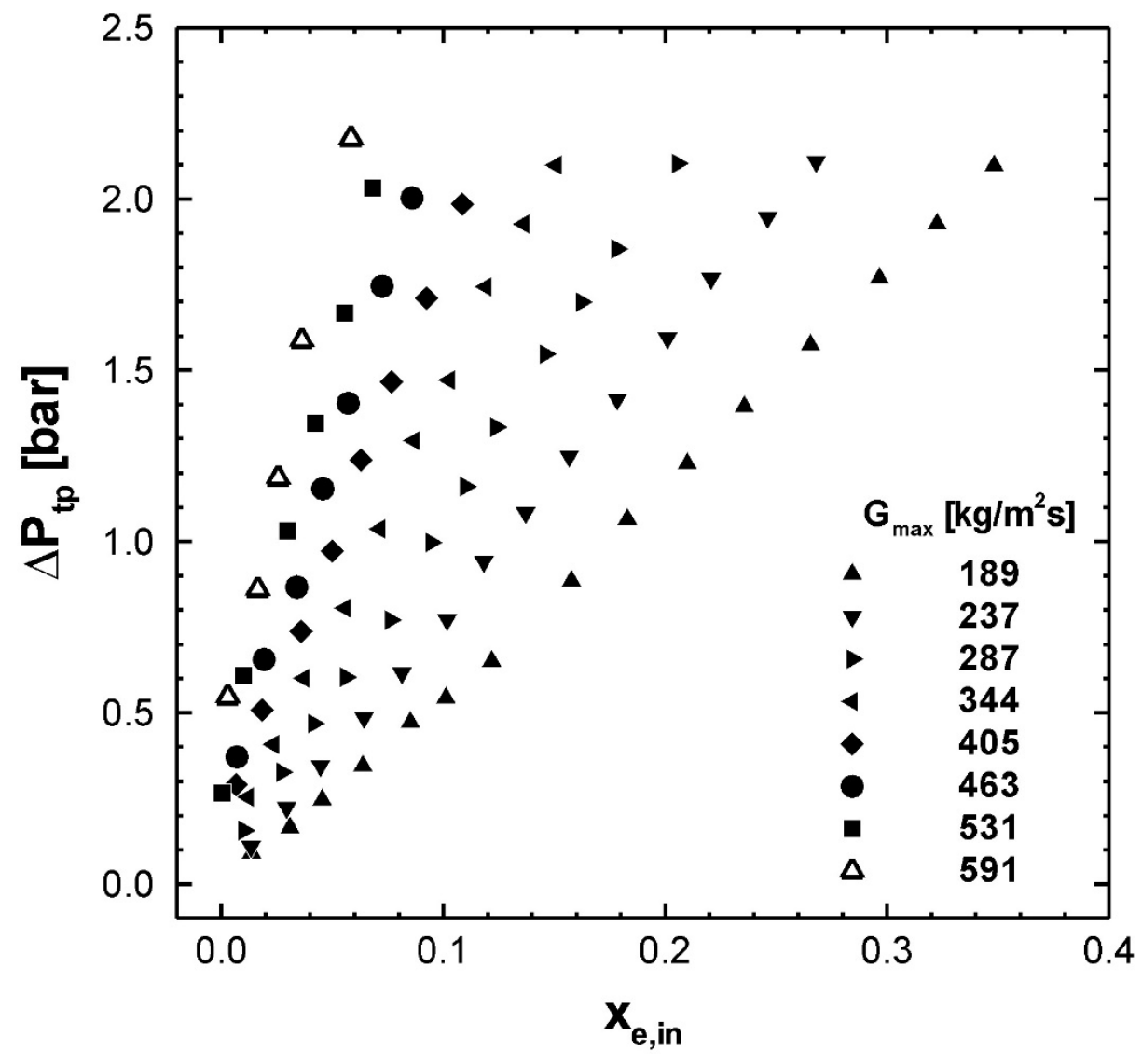

Fig. 6 


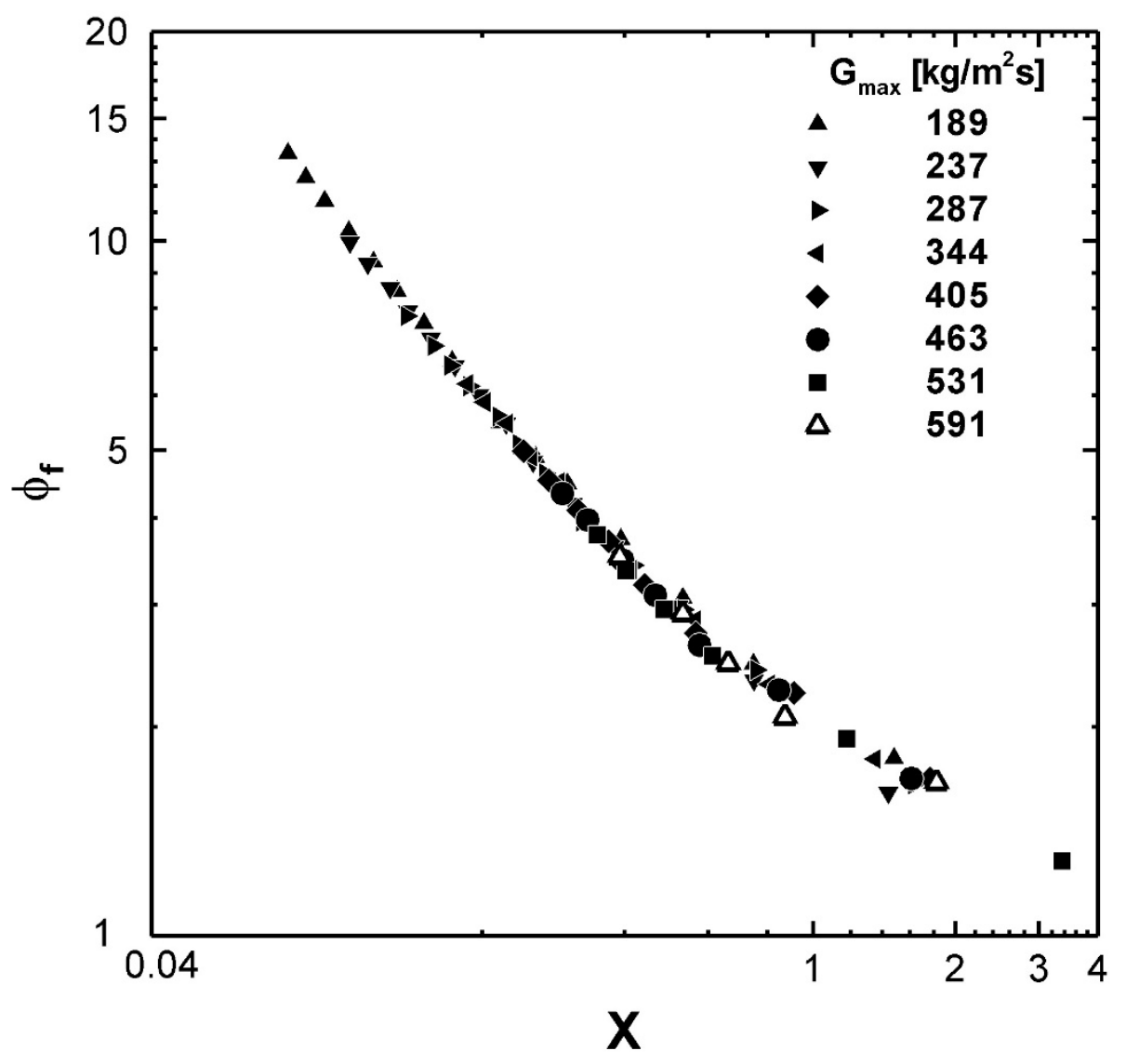

Fig. 7 


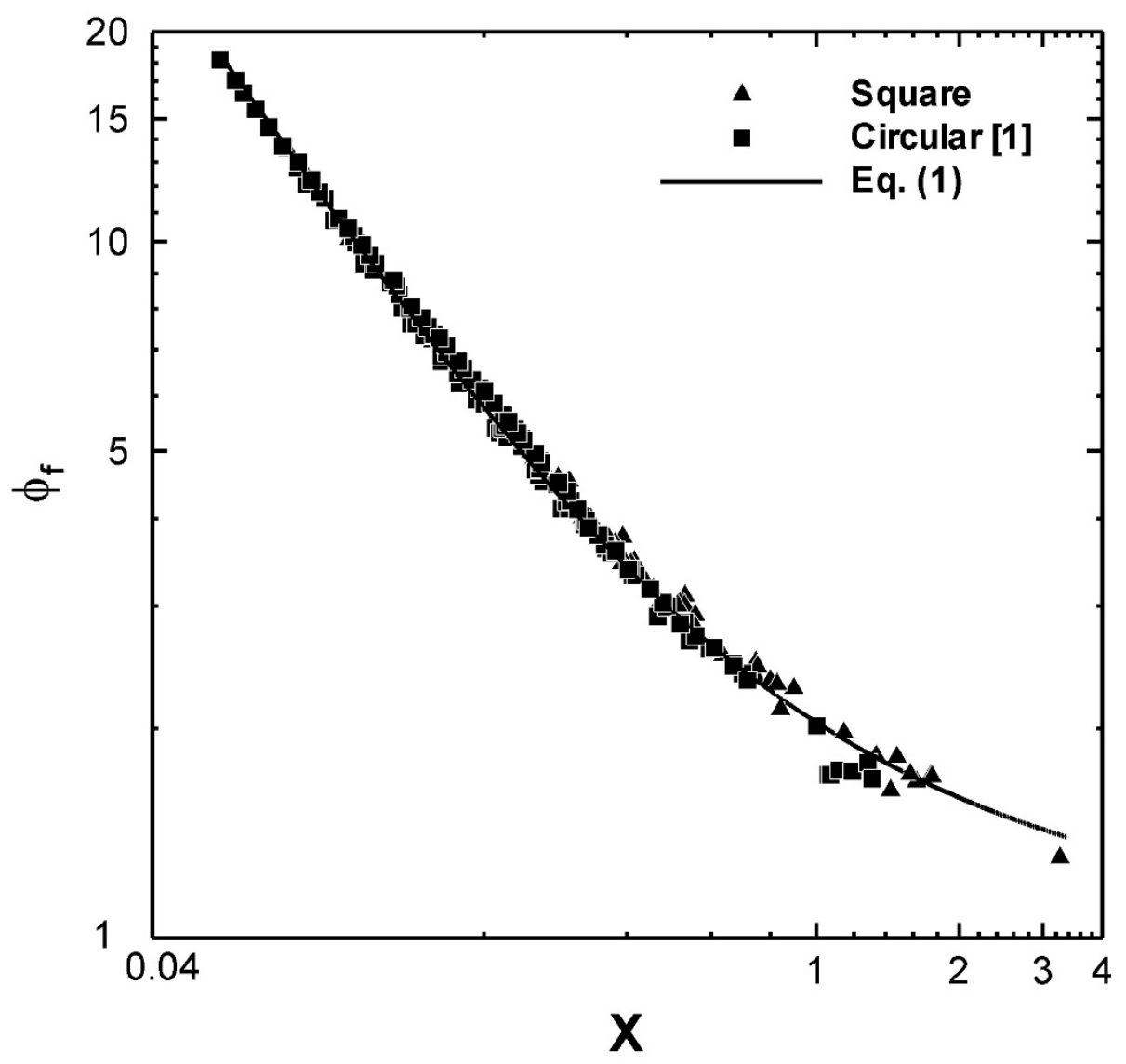

Fig. 8 


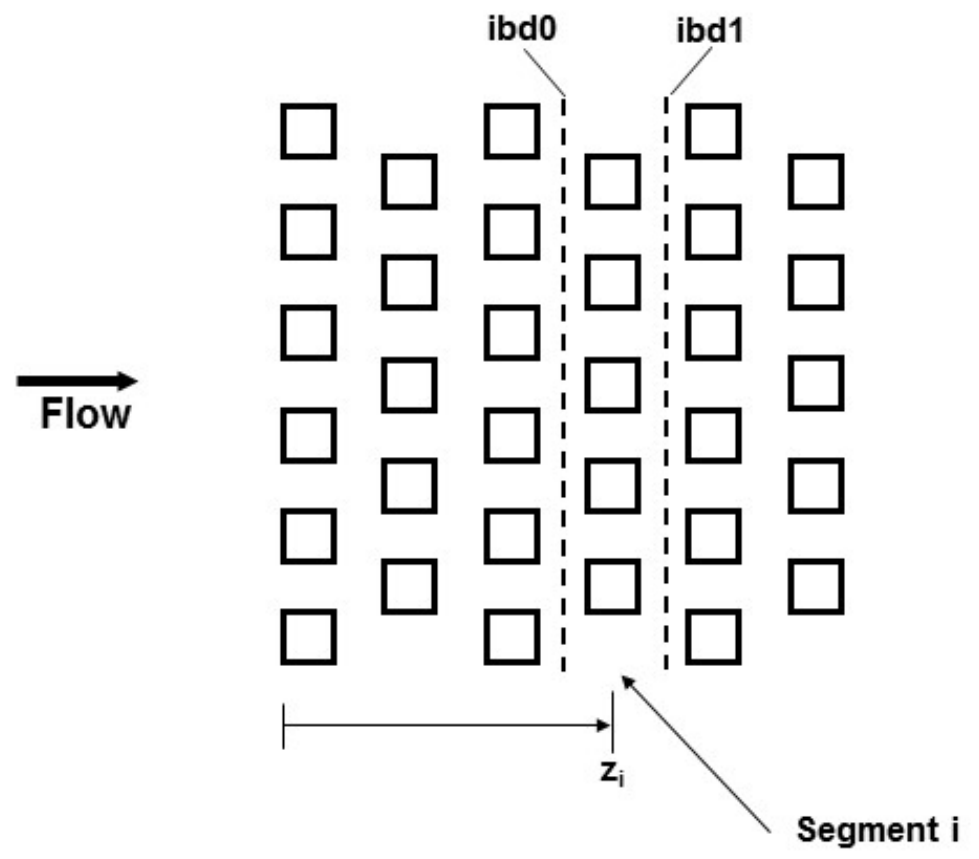

Fig. 9 


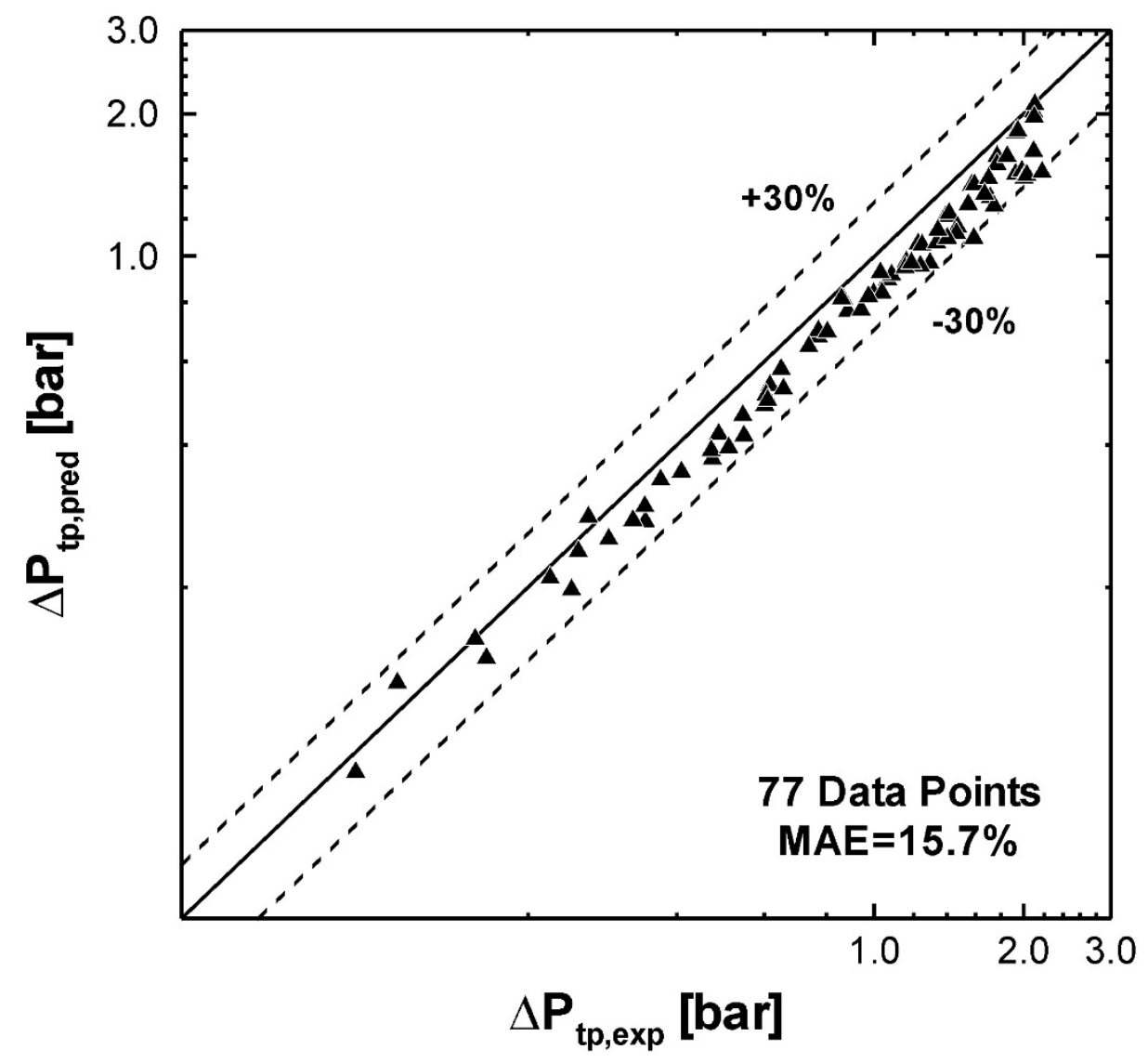

Fig. 10 